\title{
A Dinâmica dos núcleos na produção de significados para a Álgebra Linear
}

\author{
Amarildo Melchiades da Silva \\ Universidade Federal de Juiz de Fora / UFJF \\ Departamento de Matemática \\ amarildo.melchiades@ufjf.edu.br
}

\begin{abstract}
Resumo
Neste artigo apresentamos uma investigação sobre a dinâmica dos núcleos no processo de produção de significados de estudantes para a Álgebra Linear. O objetivo da pesquisa foi o de ampliar nosso entendimento sobre esta noção presente no Modelo dos Campos Semânticos a partir do estudo de sua dinâmica. A pesquisa caracterizou-se por uma abordagem qualitativa de investigação, cujo trabalho de campo foi desenvolvido em uma sala de aula da disciplina Álgebra Linear. A coleta de dados aconteceu a partir do momento em que um problema foi proposto à turma e que desencadeou a produção de significados dos estudantes na direção de encontrar sua solução. A observação teve duração de, aproximadamente, dois meses, em que alunos divididos em grupos investigaram a resolução do problema. A análise da dinâmica do processo foi elaborada, considerando as ações enunciativas dos sujeitos de pesquisa. $\mathrm{O}$ estudo revelou que esses sujeitos produziram significados diferentes para o problema proposto e, como consequência, observou-se a constituição de diferentes núcleos, sugerindo que não há uma dinâmica dos núcleos, mas dinâmicas peculiares a cada sujeito.
\end{abstract}

Palavras-chave: Educação Matemática. Produção de Significados. Núcleo. Dinâmica. Álgebra Linear.

\section{Kernel dynamics in production meaning for linear algebra}

\begin{abstract}
With this study we present research on kernel dynamics in the meaning production process as developed by Linear Algebra students. The research was aimed at broadening our understanding about the topic subsumed under the Semantic Field Model from a perspective of its dynamics. The study took a qualitative approach to the matter, whose fieldwork was carried out within a Linear Algebra classroom. Data collecting started from the moment a problem was presented to the classroom group and meaning production was recorded towards finding a solution to this problem. Observational period took approximately two months, during which students split into groups and researched into solving the problem. Dynamics analysis was designed considering the participants' utterances. The study showed that participants produced different meanings to the problem posed and as consequence different kernels were formed, suggesting that there is not a single kernel dynamics but, rather, types of dynamics peculiar to each individual.
\end{abstract}


Keywords: Mathematics Education. Meaning Production. Kernel. Dynamics. Linear Algebra.

\section{Introdução}

Este artigo apresenta uma investigação que buscou o entendimento sobre a dinâmica dos núcleos, uma das noções categorias do Modelo dos Campos Semânticos (MCS) proposto por Lins (1997, 1999, 2001, 2012) e que nos permite, em termos práticos, entender a maneira de operar de nossos estudantes quando falam de matemática. O estudo foi desenvolvido em uma sala de aula de Álgebra Linear em que os estudantes estavam envolvidos na atividade de resolver um problema proposto pelo professor. O presente artigo é parte de um estudo mais amplo sobre a dinâmica da produção de significados para a matemática presente em Silva e Lins (2013).

O MCS é um modelo epistemológico que possui uma caracterização para significado e produção de significados, termos chave nesse estudo. Significado de um objeto deve ser entendido como aquilo que o sujeito pode e efetivamente diz sobre um objeto no interior de uma atividade ${ }^{1}$. Como decorrência desta concepção, dizer que um sujeito produziu significados é dizer que ele produziu ações enunciativas para um objeto no interior de uma atividade. Além disso, produzir significados não se refere a tudo o que, em dada situação, o sujeito poderia ou deveria dizer de um objeto, e sim o que ele efetivamente diz sobre aquele objeto no interior daquela atividade. (LINS; GIMENES, 1997, p.145). Os objetos, por sua vez, são constituídos enquanto tal a partir do que o sujeito diz que eles são.

Dessa perspectiva teórica, quando analisamos as ações enunciativas (fala, gestos, registro escrito, registros no quadro) de nossos sujeitos de pesquisa, nosso olhar se dirige para o que designamos noções categorias. Assim, em nossa análise, consideramos que quando uma pessoa se propõe a produzir significados para o resíduo de uma enunciação, observamos o desencadeamento de um processo - o processo de produção de significados - que envolve: i) a constituição de objetos coisas sobre as quais sabemos dizer algo e dizemos - que nos permite observar tanto os novos objetos que estão sendo constituídos quanto os significados produzidos para esses objetos; ii) a formação de um núcleo: o conjunto das estipulações locais, iii) a maneira de operar dos sujeitos e sua lógica; iv);

\footnotetext{
${ }^{1}$ No sentido proposto por Leontiev: por atividade, designamos os processos psicologicamente caracterizados por aquilo a que o processo como um todo se dirige (seu objeto), coincidindo sempre com o objetivo que estimula o sujeito a executar esta atividade, isto é o motivo (VIGOTSKI; LURIA; LEONTIEV, 1988, p.68).
} 
a fala na direção de interlocutores ${ }^{2}$; e, v) as legitimidades, isto é, o que é legítimo ou não dizer, pelo sujeito, no interior de uma atividade.

A observação das ações enunciativas dos sujeitos de pesquisa na direção de resolver o problema proposto foi o ponto de partida para investigarmos a hipótese de que os núcleos possuiriam uma dinâmica, que se identificada e analisada, ampliaria nossa compreensão do processo de produção de significados relativo à maneira de operar dos estudantes quando resolvem problemas em matemática (aqui, em particular, um problema em Álgebra Linear).

A importância desse estudo está, exatamente, na ampliação de nosso entendimento da maneira de operar dos alunos em situações reais de sala de aula que permitirá aos pesquisadores que usam o MCS e aos professores que utilizam os pressupostos da teoria pensarem em caminhos que apontarão para ações concretas de interação entre professor e aluno e possibilidades de intervenção advindas da leitura da produção de significados desses estudantes. Em particular, este estudo poderá auxiliar na compreensão, análise e tratamento de dificuldades de aprendizagem que se apresentam em sala de aula.

\section{O que são núcleos?}

A noção de núcleo foi inspirada nas ideias de Nelson Goodman (1984), filósofo estadunidense que defende uma filosofia "construtivista" ou uma filosofia do entendimento, em seus próprios termos. Jerome Bruner (1997), em seu livro "Realidade mental, mundos possíveis", faz uma leitura das ideias de Goodman que, para ele, defende uma filosofia construtivista; sobre isso ele diz:

Sua tese central, o "construtivismo", é a de que, ao contrário do senso comum, não existe um "mundo real" único que preexista e que seja independente da atividade mental humana e da linguagem simbólica humana; o que chamamos de mundo é um produto de algumas mentes cujos procedimentos simbólicos constroem o mundo. (BRUNER, 1997, p.101)

Sobre a construção e multiplicidade de mundos, Bruner comenta:

O mundo da aparência, o próprio mundo em que vivemos, é "criado" pela mente. A atividade de elaboração do mundo é, para Goodman, um conjunto diverso e complexo de atividades, e sejam quais forem as outras formas pelas quais ele se expressa, as mesmas envolvem a "elaboração não com mãos, mas com mentes, ou melhor, com linguagens ou outros sistemas de símbolos [...]". Os mundos que criamos, segundo ele, podem surgir da atividade cognitiva do artista (o mundo de Ulisses e de Joyce) ou das ciências (seja visão geocêntrica do mundo da Idade Média ou da física moderna), ou da vida comum (como no mundo do juízo comum dos trens, couves e reis). Tais mundos (ele insiste) foram construídos, mas sempre a partir de outros mundos, criados por outros, os quais tomamos como dados. Não

\footnotetext{
2 "O interlocutor é uma direção na qual se fala. Quando falo na direção de um interlocutor é porque acredito que este interlocutor diria o que estou dizendo e aceitaria/adotaria a justificação que me autoriza a dizer o que estou dizendo" (LINS, 2012, p.19).
} 
operamos em algum tipo de realidade primitiva independente de nossas próprias mentes ou das mentes daqueles que nos precederam ou nos acompanham. (BRUNER, 1997b, p.102)

Para Goodman, o real é uma construção mental na qual certas partes - as estipulações ficam intocadas, de modo a produzir o efeito psicológico que descrevemos como realidade. A noção de estipulação, isto é, de tomar algo como dado, inspirou a noção de núcleo a partir da ideia de estipulações locais da seguinte maneira: no processo de produção de significados, existem algumas afirmações que a pessoa faz e que, tomando-as como absolutamente válidas, não sente necessidade de justificá-las. A essas crenças-afirmações, chamaremos de estipulações locais. E ao conjunto de estipulações locais constituídas no interior de uma atividade denominamos núcleo. Nesta direção, Lins (1997, p.194) comenta:

Os elementos de um núcleo funcionam como estipulações locais: localmente são "verdades absolutas", coisas que assumimos sem que haja a necessidade de uma infinita cadeia regressiva de justificações. O que é importante e revelador é que esse "localmente" se refere ao interior de uma atividade, e que no processo dessa atividade esse núcleo pode se alterar pela incorporação de novas estipulações (elementos) ou pelo abandono de algumas estipulações até ali assumidas.

Ainda na direção de esclarecer a noção de núcleo, Lins (1997, p. 144) observa:

Um núcleo pode ser constituído por um diagrama, por um desenho, por uma balança, por um conjunto de princípios (axiomas, por exemplo), por uma situação "realista" ou ficcional. O que importa é que é em relação aos objetos do núcleo que vai ser produzido significado, seja para que texto for. Núcleos não se referem especificamente a "conteúdos" ou "áreas de conhecimento": em relação ao mesmo núcleo de balança de dois pratos, é possível produzir significado para uma equação, para a noção de justiça ou para fenômenos físicos diversos.

É importante ter em mente que núcleo, no sentido proposto no MCS, não se refere a algo estático, a um conjunto de coisas, e sim, a um processo que ocorre no interior da atividade em que o sujeito está envolvido.

Na observação dos núcleos, em dada atividade, podemos identificar a maneira de operar dos sujeitos bem como a lógica das operações ligadas ao processo de produção de significados para um texto. Segundo Lins (1997, p.114), "toda operação é realizada segundo uma lógica" e ele vê como essencial a investigação dessas lógicas se quisermos entender as formas de pensar de nossos alunos, de nossos sujeitos de pesquisa. Sobre o que vem a ser a lógica das operações, ele comenta que, "posto de uma forma simples, estamos nos referindo a um conjunto de estipulações, dentro de um núcleo, que se refere diretamente ao que pode ser feito com os objetos que estamos constituindo pela produção de significados" (LINS, 1997, p.145).

A noção de núcleo está associada à noção de Campo Semântico, entendida como a atividade de produzir significado em relação a um núcleo. Alternativamente, diremos que uma pessoa está 
operando em um Campo Semântico toda vez que ela estiver produzindo significado em relação a um núcleo no interior de uma atividade.

Portanto, neste artigo, nossa análise se dirige a identificar e analisar a constituição de núcleos a partir da produção de significados dos estudantes da referida disciplina.

\section{A Metodologia da pesquisa}

Esta pesquisa caracterizou-se como sendo uma abordagem qualitativa (BOGDAN; BIKLEN, 2013) do tipo etnográfico (ANDRÉ, 2009) em que a pesquisa de campo foi desenvolvida com o objetivo de analisar as ações enunciativas dos sujeitos de pesquisa.

A pesquisa de campo aconteceu em uma sala de aula de um Programa de Pós-Graduação em Educação Matemática onde estava sendo ministrada a disciplina Álgebra Linear para uma turma de dezoito alunos.

A coleta de dados foi feita a partir de filmagens das apresentações dos alunos sobre a busca por uma solução, do registro escrito da resolução do problema e da gravação de uma entrevista com cada grupo no final do processo e antes de o professor apresentar a solução do problema.

A análise que desenvolvemos, considerou a fala e registros escritos dos sujeitos de pesquisa nomeados pelos seus pseudônimos: Mila, Betty, Mel, Diva, Lufran, Role, Morgana, Pinho, Ane, Azul, Mega, Muiara, Maria Luiza, Ades, Judy, Teka, Duda. Neste artigo, em particular, nosso foco estará na produção de significados de Betty, Ades e Azul.

O desencadeamento do processo de investigação aconteceu a partir da proposição do seguinte problema apresentado no quadro negro pelo professor à turma para ser resolvido:

\section{Quadro 1 - Problema}

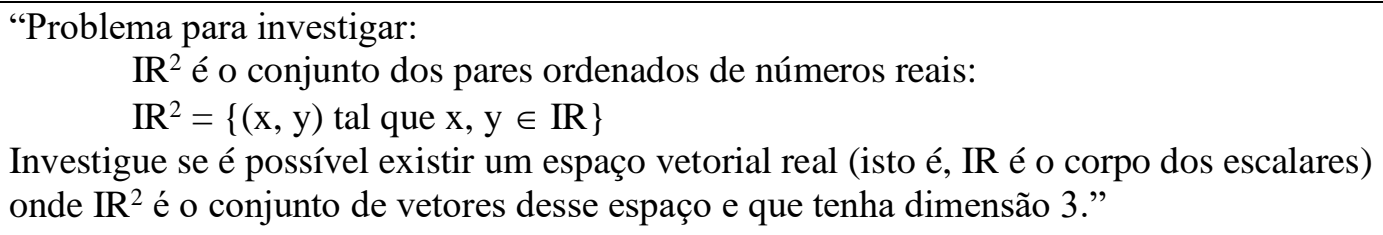

A principal característica desse problema, do ponto de vista matemático, é que para solucioná-lo o estudante deveria pensar no espaço vetorial $\mathrm{IR}^{2}$ como a estrutura algébrica. Além disso, o problema possuía a característica de ser familiar - no sentido de que os estudantes soubessem dizer alguma coisa sobre o que foi enunciado, por exemplo, sobre o $\mathrm{IR}^{2}$ - e ser não-usual, no sentido que ele não funcionasse como um exercício, mas como um problema que demandasse um certo esforço cognitivo para solucioná-lo, como de fato aconteceu. 
Da perspectiva dos significados que um matemático produziria na tentativa de resolução desse problema, seria necessário considerar a definição de espaço vetorial, entendido como uma estrutura algébrica constituída por um conjunto, um corpo e duas operações (a adição de vetores e a multiplicação por escalar).

Analisando o problema, dentro das condições dadas, se as operações forem as usuais, temse que a dimensão do espaço vetorial procurado é 2 . Sendo assim, a questão passa a ser: existem operações não-usuais que satisfaçam às condições do problema? A resposta a esta pergunta é sim. Porém, ao chegar à tal conclusão, fica a questão de como determinar tais operações de modo que o espaço vetorial em questão tenha dimensão três. O que esse problema sugere é o fato de que, dependendo da operação que se escolhe, a dimensão pode ser diferente.

O problema ficou em discussão em sala de aula por aproximadamente dois meses e os alunos, divididos em grupos, se revezavam com apresentações semanais no quadro negro, atualizando o grupo (docente e alunos) dos progressos que estavam tendo na resolução do problema.

A análise que descreveremos a seguir pretende sugerir a dinâmica dos núcleos dos sujeitos de pesquisa. Selecionamos para isto a produção de significados de Betty, Ades, Diva e Azul porque elas foram determinantes para a compreensão do que estávamos investigando.

\section{A produção de significados de Betty}

Na primeira produção de significados de Betty sobre o encaminhamento de seu grupo para a resolução do problema, uma questão é colocada de imediato por ela: $(x, y, 0)$ equivale a $(x, y)$ ? Essa questão parece surgir em decorrência da sua maneira de operar. Ao falar, ela constitui os seguintes objetos: vetores, dados por pares e ternas; $\mathrm{IR}^{3}$, como o objeto que possui vetores da forma $(\mathrm{x}, \mathrm{y}, \mathrm{z}) ; \mathrm{IR}^{2}$, como o objeto que possui vetores da forma $(\mathrm{x}, \mathrm{y})$. Em suas ações enunciativas, ela faz um esboço na lousa, sugerindo a representação cartesiana do espaço como um sistema ortogonal de eixos coordenados. Ela diz:

Betty: (x,y) coincide geometricamente em R2, tipo, considera esse plano, né?, que seria meu R2 [vide figura 1]. Mas, se eu tô trabalhando no R3, equivale a dizer a mesma coisa? [...] Tipo, eu posso pegar um plano aqui também [ela indica um outro plano] e aí? Vai ser um vetor pertencente ao R2 também? ${ }^{3}$

\footnotetext{
${ }^{3}$ Nas transcrições das falas as seguintes convenções foram utilizadas: a) Os sujeitos de pesquisa são identificados pelos seus pseudônimos e o professor pela abreviação Prof.; b) Colchetes são usados para indicar gestos, expressões e atitudes dos sujeitos de pesquisa; c) Palavras entre barras indicam sobreposição de falas; d) Uma barra indica interrupção súbita ou mudança na direção de uma fala; e) Reticências indicam pausa prolongada; f) Reticências entre colchetes indicam omissão de partes da transcrição; g) Aspas em uma citação indicam que o sujeito de pesquisa está lendo o que está dizendo; h) Usaremos a notação IR2 e IR3, para indicar a maneira como o sujeito de pesquisa se referia em sua fala ao $\mathrm{IR}^{2}$ e IR $\mathrm{IR}^{3}$, respectivamente.
} 
O esboço na lousa constitui uma estipulação local para Betty. São também suas estipulações locais: $\mathrm{IR}^{3}$ é o espaço, $\mathrm{IR}^{2}$ é o plano no espaço e $\mathrm{IR}^{2}$ está contido em $\mathrm{IR}^{3}$. Betty parece estar falando na direção dos significados geométricos que nos remete aos objetos da Geometria Analítica.

$\mathrm{Na}$ aula seguinte, Betty, dialogando com Duda, Maria Helena e Teka, faz comentários que reunimos na seguinte transcrição:

Betty: Eu só queria colocar uma coisa. Se você olhar pra R2 como sendo elementos de um conjunto e a partir disso você definir operações de modo que tenha dimensão três, você ainda continuaria olhando desse modo? [...] Tipo assim, cê tem R2, seu conjunto de vetores, tá? A partir disso, é possível você definir operações de modo que eu não vá olhar para o par ordenado x,y? [...] tipo, eu vou somar vetores x mais y de uma maneira que eu não faça a mesma coisa que eu tô acostumada a fazer no plano usualmente, de modo, vão supor, a obter uma terna, não sei. [...]. Então, é, será que não seria o caso de definir uma operação pra tá determinando um espaço vetorial de dimensão 3? Porque da maneira que vocês fizeram, deu a impressão que, ao fazer dessa forma, o conjunto R2 com as operações usuais, aí sim vai ter dimensão dois. Aí eu mudaria a pergunta: será que tem uma outra operação que isso ocorra?

Nesse momento, observamos que ela está incorporando novos objetos a sua fala e parecia estar mudando a direção do que disse em relação a aula anterior. A sua leitura do problema proposto parece ser: determinar um espaço vetorial de dimensão 3 a partir de uma operação diferente. Ela introduz a ideia de operação constituída em objeto pelas seguintes características: ser usual ou não, envolver pares e ternas, tal que, somar dois pares pode resultar em uma terna. Vemos que ela opera, ainda, com os seguintes objetos: espaço vetorial, dimensão e base e com a seguinte estipulação local - o conjunto $\mathrm{IR}^{2}$, com as operações usuais, tem dimensão 2. Observamos ainda que, apesar de Betty dizer "o conjunto IR2", ela parece operar como se ele fosse um espaço vetorial.

Ao final da aula, ela faz o seguinte comentário:

Betty: Se a gente conseguisse definir uma operação em cima do R2, de modo que a gente obtivesse uma base com três vetores, aí sim a gente chegaria. Mas o problema é: como fazer isso? Agora, se a gente não conseguir? Como provar que não, entendeu? Se não for possível, claro, como provar que não?

Sua maneira de operar fica melhor esclarecida quando ela faz o seguinte comentário acerca desse momento:

Betty: [...] Pra mim é assim: se existisse o isomorfismo, então eu conseguiria é definir as operações de soma e multiplicação de modo que o conjunto tivesse dimensão três. Mas aí a gente até ficou tentando achar [...] eu tava tentando mesmo definir bonitinho, achar uma operação tipo somando $(a, b)$ mais $(c, d)$, vai dar quem? Eu queria que desse uma terna. Na última reunião do nosso grupo, a gente tava querendo que isso virasse uma terna, mas não sai. Fiquei pensando, pensando.

Nesse momento, vemos que a ideia de isomorfismo está sendo uma estipulação local a partir da qual ela opera. Além disso, em diálogo com Mega, ao vê-lo dizer: "onde R2 é o conjunto de vetores 
desse espaço", ela, imediatamente, diz: "O espaço é o espaço vetorial". Reunindo essa estipulação local com a anterior - o conjunto IR2, com as operações usuais, tem dimensão 2 -, podemos observar aqui um processo de transformação sutil em relação às produções de significados anteriores e posteriores. A sugestão para detectá-lo nos foi indicada por Betty, durante entrevista que realizamos com seu grupo. Ela disse:

Betty: Eu acho que a maior dificuldade nossa, nesse problema, no começo, foi enxergar R2 como conjunto. A gente tava pensando nele como espaço. Aí é que a gente começou a falar e se R2 for o próprio espaço, né? [...] Aí a gente passou a ver o subespaço e tal. Aí, é que depois a gente falou não, vamos ver como conjunto, mas pra dar esse salto aí, foi tempo.[...] Mas, mesmo a gente lendo, R2 conjunto de vetores, a gente não viu como conjunto, a gente via como sendo espaço.

Assim, como havíamos sugerido anteriormente, Betty considerou IR2 como um espaço vetorial. Em sua intervenção, na aula seguinte, com o propósito de resolver o problema, ela diz:

Betty: [...] eu defino o meu espaço [ela escreve na lousa: $\left.V=\left(\mathrm{IR}^{2},+, *\right)\right]$. Seria o meu espaço procurado, cujo conjunto de vetores sejam R2 e tenha dimensão três. E eu quero verificar o quê? [Ela mesma responde] Se ele tem dimensão três. Pra isso o que que eu preciso? Encontrar uma base de vetores que eu não sei quem é [ela escreve na lousa: $\beta=\{(),(),()\}]$, que gere todo esse conjunto [referindo-se a V]. Então, quer dizer, se tiver três vetores e esses vetores forem L.I., eu consigo ver que este espaço tem dimensão três. Então, se existir uma bijeção com o R3 [ela esboça o diagrama da figura 1], eu consigo encontrar essa base. Por quê que eu consigo? Vocês me dêem uma base em R3.

$$
\mathrm{V}=\left(\mathrm{IR}^{2},+, *\right)
$$

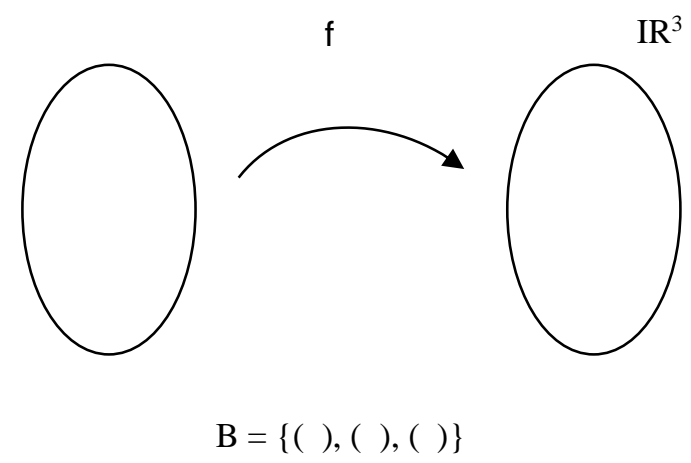

Figura 1

Pinho: Base canônica.

Betty: Base canônica, mas qual seria?

Pinho: Um, zero, zero; zero, um, zero; zero, zero, um [e ela escreve na lousa - vide figura 2]. 


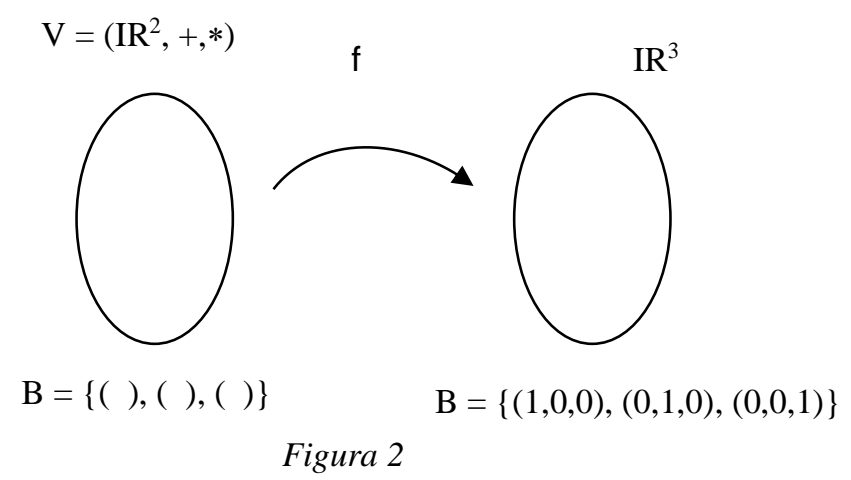

Betty: Então, assim, aqui é uma base. Agora, se existir essa bijeção, eu posso tá definindo as operações é..., em função dessa função bijetora [referindo-se a função $f$ da figura 2]. Porque daí eu pego aqui e trago pra cá [ela indica com um gesto o caminho de R3 para V]. Ou seja, pra essa base eu consigo os elementos / os vetores dessa base.

Note que $\mathrm{V}=\left(\mathrm{IR}^{2},+\right.$,*) é constituído em objeto como o espaço vetorial procurado - formado por $\mathrm{IR}^{2}$ e duas operações não-usuais - que deve ter dimensão 3. Ela então se propõe a encontrar uma base de V, tal que, como ela diz, "se tiver três vetores e esses vetores forem L.I., eu consigo ver que este espaço tem dimensão três". Ao dizer isso, sou levado a pensar que ela está operando com a noção algébrica de dimensão. Observo também que Betty, como indica sua fala e o esboço gráfico, opera com $\mathrm{V}$ e $\mathrm{IR}^{3}$ como sendo espaços vetoriais, mas faz menção a eles, por vezes, chamando-os de conjunto. Além disso, ela está operando de modo a aplicar a função f aos espaços vetoriais.

Sobre a bijeção, na continuação, ela diz:

Betty: Eu tô usando pelo seguinte fato: eu queria definir as operações nesse conjunto [ela indica $V$ na lousa] de modo que esse conjunto tivesse dimensão três. Só que, pra isso a gente estabelece uma relação com o R3. Então, pra eu definir a soma, eu definiria como? [Ela vai contando e escrevendo na lousa] Eu pegava, vão supor, dois vetores $(a, b)$ mais $(c, d)$, aí eu esqueço um pouco isso aqui pra ver como eu fui definindo as operações em R3. Como é feita se eu tivesse a função, essa bijeção, de V em R3. A operação aqui seria [ela escreve na lousa: $(a, b) \oplus(c, d)=f^{-1}(f(a, b)+$ $\mathrm{f}(\mathrm{c}, \mathrm{d}))$ ]. Aqui seria a operação usual e aqui seria a operação em $\mathrm{V}$, tá? Só que isso, existindo a bijeção, é o mesmo que eu fazer isto aqui. Então eu deveria ter usado a função bijetora na operação, pra conseguir a operação. Porque eu não conseguiria enxergar como eu opero em R3 e volto pro meu conjunto V. Aqui seriam os elementos de R2 e aqui de R3. [Na lousa ela verifica o que escreveu: $(a, b) \oplus(c, d)=$ $f^{-1}(f(a, b)+f(c, d))$ e ela indica que $f(a, b)=(x, y, z)$ e $\left.f(c, d)=\left(x^{\prime}, y^{\prime}, z^{\prime}\right)\right] \cdot[\ldots]$ Então a multiplicação por escalar seria $\alpha$ de (a,b) e eu vou pensar que eu tô operando em R3, no caso. E a imagem inversa para que eu caia no conjunto $V$. Não sei se tá claro a notação que eu tô fazendo [ela registra na lousa $\alpha \cdot(a, b)=\alpha \cdot f^{-1}(f(a, b))$ e indica $f(a, b)$ $=(\mathrm{x}, \mathrm{y}, \mathrm{z})]$.

[...] Eu aplico f, eu caio aqui, eu tenho uma terna [indicando o $\mathrm{IR}^{3}$ na figura 2]. Então aqui eu tô operando com ternas e volto pra cá, eu tenho pares [referindo-se a V na figura 2]. Só que aqui, se eu tenho uma base, 1.i., com três vetores [indicando o IR3 na figura 2], a minha base aqui também vai ser 1.i. com três vetores. Portanto, dimensão três. 
No início de sua fala anterior, ela segue dizendo conjunto V e operando de modo a constituílo como espaço vetorial; por exemplo, ela diz: "de modo que esse conjunto tenha dimensão 3".

Assim, ao produzir significados, Betty constitui os seguintes objetos: vetor (como pares e ternas), bijeção, imagem inversa [leia-se inversa da função], espaço vetorial, base, vetores 1.i., dimensão, transformação linear, operações usuais e não-usuais $\left((a, b) \oplus(c, d)=f^{-1}(f(a, b)+f(c, d))\right.$, $\left.\alpha .(a, b)=\alpha \cdot f^{-1}(f(a, b))\right)$ e isomorfismo. Sobre o objeto isomorfismo, ela diz: "Tá definido assim, 'entende-se por isomorfismo do espaço vetorial $U$ no espaço vetorial $V$ uma transformação linear $f$ de U em V que seja bijetora. Um isomorfismo f de U em U é um automorfismo de U' [lendo]”. Nesse momento, ela está operando segundo as seguintes estipulações locais:

- "O IR ${ }^{3}$ tem dimensão três";

- Se f é bijetora, então existe a imagem inversa de f;

- $\quad \mathrm{IR}^{3}$ é um espaço vetorial;

- f, bijetora, não é definida por uma lei;

- Se um espaço vetorial possui um conjunto de três vetores 1.i., então a dimensão desse espaço é três;

- Uma base do espaço gera todo o espaço.

A operação é “associar” V e IR ${ }^{3}$ através da ação da função bijetora f, de modo a tomar uma base do espaço vetorial $\mathrm{IR}^{3}$ e associá-la a uma base de $\mathrm{V}$, o que implica, como ela mesma diz, em relacionar par e terna e não implica em transformar par em terna.

Nas aulas seguintes, Betty e seu grupo continuam a produzir significados na direção de resolver o problema proposto. Em sua produção de significados, Betty vai constituindo os seguintes objetos em sua fala: transformação linear, função bijetora, teorema de Cantor, as propriedades ligadas às operações de adição e multiplicação por escalar da definição de espaço vetorial, entre outros objetos. Ao longo do tempo os objetos $\mathrm{IR}^{2}$ e $\mathrm{IR}^{3}$ passaram por um processo de mudanças na sua constituição. Em um primeiro momento, ela os constituiu como espaços vetoriais, mas sem menção à estrutura algébrica. Aos poucos foi ficando claro em que momento eles deveriam ser entendidos como conjuntos e em que momento eles deveriam ser constituídos como espaços vetoriais. Ela então conclui que, na bijeção $\mathrm{f}: \mathrm{IR}^{2} \rightarrow \mathrm{IR}^{3}$, esses objetos são conjuntos e, na transformação linear $\mathrm{T}: \mathrm{V} \rightarrow \mathrm{IR}^{3}$, tais objetos têm uma estrutura de espaço vetorial indicada da seguinte maneira: $\mathrm{V}=\left(\mathrm{IR}^{2}, \oplus, *\right) \mathrm{e} \mathrm{IR}^{3}=\left(\mathrm{IR}^{3},+, \cdot\right)$.

A constituição do núcleo foi se dando a partir das seguintes estipulações locais:

- $\quad \mathrm{IR}^{3}$, com as operações usuais, tem dimensão 3;

- $\quad \mathrm{IR}^{2}$, com as operações usuais, tem dimensão 2; 
- $\mathrm{f}: \mathrm{IR}^{2} \rightarrow \mathrm{IR}^{3}$, bijetora, existe, pela função de Cantor;

- As operações em jogo são as operações de adição e multiplicação por escalar, dadas por: $(\mathrm{a}, \mathrm{b}) \oplus(\mathrm{c}, \mathrm{d})=\mathrm{f}^{-1}[\mathrm{f}(\mathrm{a}, \mathrm{b})+\mathrm{f}(\mathrm{c}, \mathrm{d})]$; e

$\alpha \cdot(a, b)=f^{-1}[\alpha \cdot f(a, b)]$.

- $\mathrm{T}: \mathrm{V} \rightarrow \mathrm{IR}^{3}$ é linear.

Assim, na leitura do processo de produção de significados de Betty observamos que houve um processo de transformação dos objetos IR2 e IR3 durante a produção de significados de Betty. Ao longo do processo, vários significados foram produzidos por Betty para esses objetos. Em sua primeira fala, $\mathrm{IR}^{2}$ é o conjunto de pares ordenados e $\mathrm{IR}^{3}$ é o conjunto de ternas ordenadas. Instantes depois, ela faz um esboço na lousa, indicando que naquele momento $\mathrm{IR}^{3}$ era constituído como o espaço (geométrico) e o $\mathrm{IR}^{2}$ eram os planos que constituíam o $\mathrm{IR}^{3}$. Em produções de significados posteriores, $\mathrm{IR}^{2}$ e $\mathrm{IR}^{3}$ são vistos como espaços vetoriais, mas pensados, por vezes, como conjuntos, para finalmente tomar esses objetos, na bijeção, como conjuntos e, na transformação linear, como tendo uma estrutura algébrica.

Observamos, no decorrer da produção de significados de Betty, o afastamento de certas estipulações locais, como se elas afastassem das enunciações de Betty e a transformação de outras no núcleo. Mais especificamente, após a primeira fala de Betty, o esboço gráfico representando o sistema de eixos coordenados tridimensional não apareceu mais nas justificações de Betty, como também as estipulações locais: $\mathrm{IR}^{2}$ é o plano, $\mathrm{IR}^{3}$ é o espaço. Não se viu mais, em qualquer momento, vestígios de produção de significados "geométricos" sendo produzidos. Por outro lado, $\mathrm{V}=\left(\mathrm{IR}^{2}, \oplus, *\right)$ e $\mathrm{IR}^{3}=$ $\left(\mathrm{IR}^{3},+, \cdot\right)$ vão se constituindo em estipulações locais. Houve também, ao longo do processo de nucleação, a incorporação de novas estipulações locais ampliando o núcleo.

Há um processo sutil de transformação do que em um momento são novos objetos e, em outro, se tornam estipulações. Esse é o caso da bijeção. Em um primeiro momento, Betty o constitui em objeto; na aula seguinte, uma semana depois, a bijeção parece ser uma estipulação local cuja ação é usada para operar na construção das operações de adição e multiplicação por escalar. Penso que tal fato ocorreria também com a função de Cantor (objeto introduzido em sua fala em um determinado momento), caso o processo continuasse. Isto porque Betty e Mel acenam para essa possibilidade quando dizem: “a propriedade existe” [Betty], “Existe e é válido [o resultado]. Então eu vou usar, né? Foi isso que a gente pensou" [Mel].

\section{A produção de significados de Ades}

Na primeira produção de significados de Ades a respeito do problema proposto, ele comenta: 
Ades: [...] Aí eu também pensei no seguinte: quando você pega dois vetores paralelos, você considera que é o mesmo vetor. Tanto é que você faz soma, regra do paralelogramo, etc., fazendo a transposição do vetor. Então, o vetor paralelo a ele mesmo, a um outro vetor é o mesmo vetor. Assim sendo todos os vetores / se você tem dois vetores paralelos que tão formando o plano, por exemplo, no fundo da sala, e você transpõe esse vetor, mexe pra cá, por exemplo, você tem um outro plano. [...] O conjunto das classes de eqüipolência, não seria R3? [...] O conjunto das classes de eqüipolência seria o R3. E daí me veio a idéia de que o espaço seria uma expansão do plano, né? Na medida em que você não considera ser diferentes, na medida que você considera os dois vetores paralelos, como sendo o mesmo vetor, então o que você está fazendo é uma expansão do próprio plano. Então o espaço seria uma expansão do próprio plano.

Ele segue explicando sua maneira de operar:

Ades: [...]Você teria vários planos que estariam em R2. Então, você teria um espaço vetorial R2. Como o plano paralelo é o plano paralelo formado por esse mesmo espaço vetorial R2, corresponderia ao mesmo plano. Na medida em que você não muda, na medida em que você tá compondo esse R 2 com dois vetores, você pode compor um outro plano desse mesmo R2 por dois vetores paralelos aos dois primeiros, você tem o mesmo plano. Então você fez uma expansão daquele plano no espaço, ou seja, você deixou de ter R2 e passou a ter R3, mas o plano continua sendo o mesmo. Por que continua sendo o mesmo? Porque você tá com dois vetores paralelos, formando um plano paralelo. E esses dois vetores são paralelos, portanto, são os mesmos vetores que formaram o R2.

[...]fixando uma coordenada, você cairia nos paralelos. E esses paralelos seriam o mesmo? Aí eu tô achando que seria porque seria classe de equivalência, né? Baseado nisso, baseado no vetor que você usa ou você transpõe o vetor e considera o mesmo vetor. Ou seja, dois vetores paralelos são o mesmo vetor, não é um vetor diferente. Desde que ele tenha mesmo módulo, mesma direção e mesmo sentido é o mesmo vetor, tá? Então dois vetores gerariam um plano. Então os dois vetores paralelos a esses dois, gerariam um outro plano paralelo. Mas que seria o mesmo, que seria equivalente [...] eu procurei enxergar melhor embora, né?, a dimensão, o limite do enxergar que eu digo, imaginar, ver mesmo mentalmente, fica nos três, né? Então eu considero que é um caminho arriscado na medida que nós tamos fazendo isso só pra três dimensões, o que nós tamos falando seria $\mathrm{n}$.

Sua maneira de operar está ligada à sua leitura do problema proposto. No enunciado do problema - investigue se é possível existir um espaço vetorial real onde $\mathrm{IR}^{2}$ é o conjunto de vetores desse espaço e que tenha dimensão 3, - ele lê: obter $\mathrm{IR}^{3}$ a partir de $\mathrm{IR}^{2}$. Assim, sua produção de significados se volta para responder esta questão.

A reconstituição de seus argumentos parece seguir, em resumo, a sequência: dois vetores paralelos são o mesmo vetor e dois vetores paralelos formam um plano; dois vetores paralelos a outros dois vetores paralelos formam planos paralelos; fixado um plano e tomando um outro plano paralelo, obtém-se o $\mathrm{IR}^{3}$.

No processo de produção de significados o objeto $\mathrm{IR}^{2}$ é o plano; $\mathrm{IR}^{3}$ é o espaço; vetor é constituído em objeto como segmento orientado; classe de equivalência refere-se a um conjunto de 
planos a partir da variação de uma coordenada e o objeto "um espaço vetorial IR2" parece referir-se a um conjunto de planos. Observamos as seguintes estipulações locais:

- $\quad \mathrm{IR}^{2}$ tem dimensão 2;

- $\quad \mathrm{IR}^{3}$ tem dimensão 3;

- Dois vetores paralelos são o mesmo vetor;

- Dois vetores paralelos formam/geram um plano.

As operações com os objetos são transposição de vetor, paralelismo de vetores e planos, expansão de planos e "visualização", ocorrendo da seguinte maneira: posso transpor vetores paralelos; dois vetores paralelos a outros dois vetores paralelos formam planos paralelos e os planos devem ser paralelos, "se você fizesse enviesado, aí não". Pois, em coerência com a operação expansão do plano, os planos têm que ser paralelos. Ele opera de modo a tentar enxergar, em oposição à maneira de operar das colegas de grupo: "E elas tentaram a partir das propriedades, pensar, mostrar que aquilo era verdadeiro ou não. E eu fui procurando enxergar". Observo que "enxergar" é entendido por Ades como uma operação legítima. Além disso, sua fala sobre dimensão - o limite de enxergar, como ele diz - nos sugere, como afirmei anteriormente, que para ele o espaço tem dimensão 3.

Porém, vemos que, apesar de operar dessa maneira, ele deixa transparecer que não considera o problema resolvido; ele diz: "Eu não consigo caracterizar bem, mas é assim que eu vejo. Exatamente isso que eu quero fazer, essa ligação de um com outro eu não consegui fazer, desde que a gente aprenda algebricamente, né?"

Ele continua produzindo significados, na direção de resolver seu problema. Vejo assim que outras estipulações locais são incorporadas, por exemplo: “eu pensei exatamente nos planos, infinitos planos, né? Porque o plano também é infinito na sua dimensão plana, né?” E segue indicando sua maneira de operar: "Então, vão dizer, pra cá é infinito, pra cá e pra lá. Na medida em que você faz vários planos paralelos, você começou a gerar o espaço, né?"

$\mathrm{Na}$ entrevista que realizamos com o seu grupo, aproximadamente um mês depois de sua primeira fala, com o intuito de saber sobre o encaminhamento do problema proposto até aquele momento, ele comentou:

Ades: [...] Pra mim ficou bem mais claro que é possível, né? Tô começando a ver com mais clareza a relação que existe entre o R2 e o R3. Pra mim, na verdade, eu venho de outra área, eu vejo de outra maneira, né? O primeiro conflito com elas duas, que são mais matemáticas, é com / não / a partir de propriedades você consegue ver. Você demonstrou a propriedade, então aquilo é verdade. Eu vejo isso de outra maneira, eu tento compreender aquilo de uma forma mais visual ou mais interpretativa, talvez, né? Eu quero enxergar que aquilo é possível. E foi nesse sentido que eu comecei a caminhar. Agora, essa semana eu vou me empenhar em transformar isso que eu tentei formular, agora, que eu chamo de ver, em operações. Porque, realmente, se você não conseguir escrever isso de uma forma inteligível, fica 
muito difícil, você explicar ou convencer alguém de que aquilo é verdade, né? Pra mim, ficou bem mais claro a questão de como aparece o R3 no R2. A princípio, tava aparecendo uma coisa meio mágica, meio desconexa, não? Porque, se você pode acrescentar ao R3, você dá mais uma dimensão, sem adulterar ou deturpar aquele vetor que era dois. De repente, ele tem mais uma dimensão, que passa a ser três. Então, isso pra mim ficou mais claro, quer dizer, que é possível. Só não consegui ainda colocar isso dentro de uma linguagem matemática explícita.

Na continuação, ele acrescenta:

Ades: É, porque, eu pensei um pouquinho nesse sentido; quando você tem dois vetores, se você pega a soma vetorial desses dois vetores, você vai ter um terceiro vetor, que vai ser coplanar, por exemplo, vai tá no mesmo plano. Se você dá uma terceira coordenada, você joga esse plano pra cima. Você continua tendo R2, num espaço três. Porque essa terceira coordenada representa a terceira dimensão. Então, pra mim, ficou mais claro. Eu, ainda, não tô conseguindo demonstrar, mas ficou mais claro que, na medida que eu tenho aquela sobreposição de planos, que a gente chegou a comentar lá / eu tô insistindo na mesma tecla [Maria Luiza e Judy riem]. Pode tá completamente errado, mas eu continuo insistindo naquilo. Você começa a formar o espaço, entendeu? Então, na medida que você tá na terceira coordenada, você tá acrescentando planos. E sempre, esse plano no espaço vetorial dois. A hora que você acrescenta a terceira, você gerou um R3.

Observamos, assim, que sua maneira de operar estava sendo mantida, que sua leitura do problema proposto ainda era a mesma: obter $\mathrm{IR}^{3}$ a partir de $\mathrm{IR}^{2}$. E sua tentativa de resolução passava por colocar suas ideias em uma linguagem matemática explícita. As operações sugerem, agora, a transformação do vetor: "você dá mais uma dimensão, sem adulterar ou deturpar, aquele vetor que era dois. De repente, ele tem mais uma dimensão, que passa a ser três”.

A última produção de significados de Ades acontece no dia em que o professor apresenta a solução para o problema proposto. O professor diz:

Prof: [...] Eu vou abrir o jogo pra vocês: é, a Betty tá certa, a resposta é sim e tudo o que ela disse é mais do que suficiente; a não ser mostrar, por exemplo, que existe a bijeção, né? Entre o R2 e o R3. E aí você pega o livro do Halmos e tá lá, né? Mesmo que você não queira acompanhar a demonstração, no livro do Halmos, tá lá.

Após tecer um comentário a respeito do que ocorreu em sala de aula, o professor diz: “Aí eu pergunto pra vocês: o que que é dimensão? Por que que a dimensão do plano é 2? O plano [ênfase no artigo o]". Isto o motivou a falar o que leva ao seguinte diálogo entre os dois:

Ades: Bom, isto porque eu tinha aprendido que o plano é de dimensão 2.

Prof: Não, mas me diz o que é / minha pergunta é: por que você diz que o plano tem dimensão 2? O plano é bidimensional? O espaço é tridimensional?

Ades: Você tem um comprimento e uma largura (ele usa o dedo indicador e o polegar para indicar) e se limita a aquilo. Você descreve um par de coordenadas, por exemplo, e daí, acaba. Eu enxergo o plano no espaço, mas eu enxergo o plano, entendeu? Como o Lufran, falou: "giro, na hora que eu girei, eu tenho um espaço", eu também acho isso, eu também vejo isso. Mas o que é girar? Eu não sei matematicamente o que é esse girar. 
$\mathrm{Na}$ continuação da conversa com o professor ele diz:

Ades: Bom, voltando ao convencional, que é a única coisa que eu posso ver, né? $\mathrm{Na}$ hora que eu coloco mais uma forma de estender esse plano, né? Quando estende, quando eu consigo estender esse plano, que é aquela idéia de um monte de planos do lado do outro (inaudível) dimensão, ou deslocar o plano. Eu vejo mais como deslocar o plano. Na hora que eu desloco o plano, eu estendo isto pra uma visão de espaço.

Note que Ades diz: "Bom, voltando ao convencional, que é a única coisa que eu posso ver, né?" Ele parece sugerir que o professor está falando de “outro lugar”, que não aquele que ele está falando. E ao dizer isso, ele pode estar dizendo que de onde ele fala também é legítimo; tanto é que ele continua falando.

A análise de toda a fala de Ades nos sugere que os objetos que ele constituiu ainda são os mesmos da sua primeira fala: vetores são segmentos orientados, representados por pares e ternas, IR ${ }^{2}$ é o plano, $\mathrm{IR}^{3}$ é o espaço. O objeto dimensão foi explicitado por ele como a quantidade de informação necessária para localizar um ponto no plano ou no espaço. Sobre dimensão dois, ele diz: "Você tem um comprimento e uma largura e se limita a aquilo. Você descreve um par de coordenadas, por exemplo, e daí, acaba”. Sobre dimensão três, ele diz: "Que eu consigo diferenciar três aspectos, vão dizer, naquilo que eu tô fazendo, naquilo que eu tô vendo, né?"

Em resumo, ao olhar para o processo de produção de significados de Ades com o intuito de pensar na dinâmica de seu núcleo, vemos a constituição dos objetos se mantendo a mesma ao longo de todo o processo: vetor, entendido como segmento orientado; $\mathrm{IR}^{2}$ é o plano, um elemento formativo do $\mathrm{IR}^{3}$; IR $\mathrm{IR}^{3}$ é o espaço; e o processo de nucleação, isto é, de constituição e transformação do núcleo, foi de incorporação de estipulações locais ao longo do processo, de maneira esquemática.

$\left[\mathrm{IR}^{2}\right.$ tem dimensão $2, \mathrm{IR}^{3}$ tem dimensão 3 , dois vetores paralelos são o mesmo vetor, dois vetores paralelos formam/geram um plano $] \rightarrow\left[\mathrm{IR}^{2}\right.$ tem dimensão $2, \mathrm{IR}^{3}$ tem dimensão 3 , dois vetores paralelos são o mesmo vetor, dois vetores paralelos formam/geram um plano, o plano é infinito, o plano é a união de dois vetores linearmente independentes, os planos geradores do $\mathrm{IR}^{3}$ são contínuos, o plano não tem espessura]

As operações foram, ao longo do processo, estender/deslocar/ acrescentar, que a meu ver, são sinônimas de expandir, como, por exemplo, "Na hora que eu desloco o plano, eu estendo isto pra uma visão de espaço"; "Quando eu tô no plano, $(2,3)$ é só $(2,3)$, se eu acrescento outra dimensão, esse ponto passa a ser vários pontos no espaço". Além disso, ele opera com o "enxergar" da seguinte maneira: "Eu enxergo o plano no espaço, mas eu enxergo o plano".

Do que observamos, constatamos que Ades produziu significados, do início ao fim, na direção de um mesmo interlocutor, independente de tudo o que ele ouviu em sala de aula. É possível que sua leitura do problema proposto tenha contribuído para esse estado de coisas. Ao entender que 
o problema a ser solucionado seria obter $\mathrm{IR}^{3}$ a partir de $\mathrm{IR}^{2}$ - isso era o novo -, ele passou a operar nessa direção. A meu ver, o problema assim entendido já havia sido resolvido por ele, na primeira aula, quando ele diz: "o espaço seria uma expansão do plano". A questão passou a ser, então, apresentar uma justificativa plausível para o professor e a turma. Por algum motivo, o que ele dizia não era satisfatório como resposta ao problema. Vimos várias vezes ele dizendo: "Eu não consigo caracterizar bem, mas é assim que eu vejo. Exatamente isso que eu quero fazer, essa ligação de um com outro eu não consegui fazer, desde que a gente aprenda algebricamente, né?” Aproximadamente um mês depois, ele diz: "Só não consegui ainda colocar isso mesmo numa linguagem matemática explícita".

A questão de saber o porquê dessa atitude já não é mais possível, tendo apenas caráter especulativo. Poderia ser porque ele acreditava que suas justificações não eram suficientes para satisfazer o professor, ou, ele acreditava que naquele espaço a justificativa aceitável deveria ser outra e não aquela que ele tinha, ou, ainda, o fato de Ades não ter encontrado nenhuma oposição à sua fala - a não ser uma divergência interna com as colegas de grupo na maneira de encaminhar a resolução do problema - pode tê-lo feito acreditar na legitimidade do que estava dizendo.

\title{
A Produção de Significados de Diva
}

\begin{abstract}
A primeira fala de Diva acontece, quando o seu grupo apresenta suas considerações sobre o problema proposto; ela diz:Diva: Oh, nas nossas anotações, o que a gente fez foi o seguinte: a gente primeiro considerou a visão do texto. $\mathrm{O}$ quê que era um espaço vetorial, em seguida, porque a gente tava querendo saber o que é dimensão, né? E como é que a gente chega para analisar a dimensão de um espaço vetorial. E aí, nós fomos chegando a conclusão do seguinte, que, por exemplo, se a gente tomar o espaço R2; o espaço R2, ele vai ter dimensão 2, né? E, por exemplo, se eu pego uma reta passando pela origem, inclusive, a reta é um conjunto de vetores do R2. Pensou uma coisa assim? Aí, prá tentar concluir o exercício dele, a gente foi analisar o seguinte; então vai ver a dimensão, os subconjuntos que estão dentro de cada espaço. A gente pensou o seguinte: oh, quando a dimensão, "o R2 é o conjunto de vetores desse espaço" (lendo na lousa e colocando ênfase no artigo o). Oh, se a gente pensar, o R2 é o conjunto de vetores desse espaço, então dá a impressão que o R2 tá coincidindo com o próprio espaço, né? Tá dando essa impressão? Agora, se por acaso, eu pensasse, por exemplo, o R2 é um conjunto de vetores deste espaço; então poderia pensar, por exemplo, que o R3 poderia ser o espaço que tivesse o espaço R2. A gente chegou a essas ideias.
\end{abstract}

Note que a questão central para Diva diz respeito à dimensão: o que é dimensão? Como analisar a dimensão de um espaço vetorial? Em sua produção de significados observamos os seguintes objetos sendo constituídos: o espaço $\mathrm{IR}^{2}$, que tem dimensão 2, tem subconjuntos de vetores; a reta, um conjunto de vetores de $\mathrm{IR}^{2}$. 
Seu núcleo é constituído pelas seguintes estipulações locais: o espaço $\operatorname{IR}^{2}$ tem dimensão 2; a reta (passando pela origem) é um conjunto de vetores de $\mathrm{IR}^{2}$; existem subconjuntos dentro de cada espaço. Ela opera com a noção estar contido, relativa a conjuntos, cuja lógica é se "o R2 é o conjunto de vetores desse espaço"; então "o R2 tá coincidindo com o próprio espaço"; ou, se "o R2 é um conjunto de vetores deste espaço”, então, “o R3 poderia ser o espaço que tivesse o espaço R2”.

Na semana seguinte, ela comenta:

Diva: Eu fiquei pensando naquela aula que o pessoal falava a respeito de plano (...). Aí eu comecei a pensar nas coisas que estão bem próximas de mim mesma, parece que eu não achei muita coisa de uma dimensão, não achei muita coisa de duas dimensões, parece que tudo tem três dimensões. Apenas eu não consegui ver como eu poderia pensar nisso daí dentro do problema dele. Então, na realidade, eu não consigo ver esse plano? Como esse plano assim, certinho, com duas dimensões. Eu não consigo ver esse plano. Eu não consigo ver também essa linha, que a gente fala: a linha tem só uma dimensão. Parece que eu consigo ver tudo, mas tudo com três dimensões. Então, eu ainda não consegui passar para a ideia do problema? Não consegui nem ver a ideia do problema. Mas eu acho assim, por mais que a gente falava assim o plano, bem fininho, bem transparente; ele deve ter uma dimensão, de espessura. Então, eu não tenho essa ideia de plano, aquele plano que não tenha as três dimensões. Eu não tenho essa ideia de linha que é uma linha com uma dimensão. Isto aí é o que tá mais me perturbando nesse exercício. Porque eu não vejo isso, não vejo isso daí, não consigo.

Neste momento, ela apresenta suas dúvidas, em particular sobre o que vem a ser dimensão. Esta questão vai segui-la ao longo de todas as aulas até o anúncio da resposta do problema. Ao longo das aulas, por vezes ela tentou falar na direção dos interlocutores de Betty, mas não consegue seguir falando de espaços vetoriais, transformações lineares, isomorfismo. Outras vezes ele tentou falar com Ades e outros colegas, mas não foi muito longe falando. Em um certo momento, ela faz um comentário importante para a compreensão do seu jeito de operar. Ela diz:

Diva: (...) Porque, na verdade, prá mim, tudo ia ser com mais de uma dimensão, não ia ter uma dimensão, não ia ter duas dimensões. Porque se eu pensar numa coisa de duas dimensões, eu vou pensar numa coisa que eu tô vendo.

Analisando este fragmento de sua fala e os registros em outros momentos vemos que ela constitui como estipulações locais as seguintes crenças-afirmações: "tudo tem três dimensões"; “o plano tem três dimensões". A última fala de Diva, quatro semanas depois sugere o estágio em que ela se encontrava na resolução do problema:

Diva: É, eu acho assim que eu ainda não avancei muito no problema, não? Pelo menos, quando eu aprendia matemática ou esses anos que eu fui professora de Matemática, sempre que a gente vai procurar a solução de um problema, a gente tem que justificar dentro de uma teoria, né? E o que tá dando trabalho nesse problema é que eu não achei o ponto onde pegar prá tentar uma teoria. Aí eu fico pensando assim, se eu saísse desse preconceito de sempre procurar uma teoria. Aí, talvez, eu achasse a solução, né? Ou pelo menos, justificasse alguma coisa ou lançasse alguma. 
Então, eu acho que é mais é isso. Eu acho que / eu venho discutindo com eles; eu falo, gente? Mas, eu abro os livros de Álgebra Linear, eu procuro alguma coisa que eu não li, alguma coisa que / eu penso assim, ah, eu acho que não entendi isso daí? Aí eu busco outra teoria; mas, isso aí eu já li, eu já vi. Isso aí não funciona prá esse caso, né? Então, aí eu fico sempre buscando a questão da teoria. Então, eu achei que eu avancei, cê entendeu? Me obrigou a rever o curso de Álgebra Linear inteiro. Acho que isso aí eu avancei, né? Fazia um tempão que eu não via essa matéria. Mas, por outro lado, eu acho assim, com relação à solução, eu acho que eu avancei pouco, continua sendo um desafio. Como é que pode uma coisa assim sem resolver? (risos) Não tem jeito não? Então, aí eu acho que a gente vai avançando (...).

Ao longo das aulas, Diva não explicita em momento algum sua leitura do problema proposto. Ela se refere ao problema proposto como "o problema dele", referindo-se ao professor. Isto nos leva a pensar na hipótese de ela não ter constituído o problema em texto. Do enunciado do problema ela extraiu a palavra dimensão, por exemplo, mas isto não permitiu que ela avançasse na compreensão do problema proposto, nem do significado algébrico de dimensão. Em algum momento das discussões ela menciona "pensar nesse espaço de dimensão 3". Isto, a meu ver, acontece mais pelo seu esforço de compartilhar o espaço comunicativo com outras pessoas do que pelo entendimento do problema. E nesse esforço ela começa a repetir as coisas que estão sendo ditas. Em decorrência deste fato as questões locais representam a tentativa de entender o que está acontecendo. Ao não conseguir falar do problema proposto ela fica presa às questões locais.

Diva parece não conseguir produzir significados para o que encontra nos livros-texto. Os objetos “o espaço R2”, “o espaço R3”, “espaço vetorial” são entendidos por ela como sendo conjuntos, sendo reta, planos, subconjuntos destes conjuntos. Ela constitui um núcleo formado pelas estipulações mencionadas anteriormente, que parecem manter-se inalteradas durante todo o processo de tentativa de resolver o problema.

\section{A Produção de Significados de Azul}

Analisaremos agora o que disse Azul a respeito do problema proposto. Sua primeira fala foi:

Azul: [...] nós nos atemos primeiro em verificar tudo isso: o que era espaço vetorial, corpo, escalar. E a primeira impressão nossa, a minha e a do Mega, era sim; e da Muiara, não. Então, nós começamos a mudar a pergunta; porque se a pergunta fosse: numa dimensão 3 as possibilidades do R2, tá? Agora, se é R2, para você chegar numa dimensão 3, não teria essa possibilidade; porque a dimensão 3, ela tem que incluir.

$\mathrm{Na}$ aula seguinte, seu grupo acreditou ter resolvido o problema proposto. Na apresentação do grupo para a turma, Azul toma a palavra e diz:

Azul: Se você tem o conjunto de vetores em R2, tá? Por mais que você trabalhar operações neles / nós vimos que era / com isto nós vimos até na outra aula / toda a parte de espaço vetorial e o que realmente era espaço vetorial, o que que acontecia, o que que precisa, por que que era? Daí, nós chegamos à conclusão que se eles 
estiverem realmente em R2, se eu não tiver nada fora dele, não tem como ter uma outra dimensão. Se fosse só pra colocar como sendo vetores de R2, pelo menos eu sinto assim. Claro, que, no início, na outra aula, nós tínhamos pensado assim: se a gente mudar / cadê a pergunta? / Se nós mudarmos a pergunta, como ela colocou também, né? Aqui, se em vez de colocar "investigue se é possível existir um espaço vetorial real e que tenha dimensão três, onde R2 é o conjunto de todos os vetores do espaço?" Se eu tô afirmando que ele tem dimensão três, daí eu consigo retirar o que é R2. Mas, no texto do jeito que está, eu acho que não dá.

O entendimento de dimensão de Azul é expressa nos seguintes termos por ela:

Azul: Claro, porque ó, vão supor, eu vou colocar, como dimensão 3, aquele canto lá da parede, tá? Então, dimensão 3 vai me dar largura e altura e profundidade, tá?

[...] Não é só, por exemplo, largura e comprimento? Não seria a dimensão 2? Largura e comprimento? Pra mim, é infinito. Mas, largura e comprimento. Quando eu tenho alguma coisa a mais, daí eu tenho dimensão três?

Ela segue esclarecendo seu ponto de vista:

Azul: [...] Pra mim, agora, ficou claro, assim, eu não vou dizer que todos. Realmente, todos, não. Mas se eu tiver dimensão 3, eu tenho certeza que eu vou ter R2. Agora, se eu tiver dimensão 2, eu tenho certeza que eu não tenho R3.

Azul vai reiterando sua fala inicial; vemos que ela não constitui o enunciado do problema em texto. Então para produzir significados, ela precisa alterá-lo. Mas, por que o enunciado do problema precisa ser alterado? Nossa resposta se baseia, primeiro, na leitura de Azul do problema. Para ela, o enunciado do problema propõe obter $\mathrm{IR}^{3}$ de $\mathrm{IR}^{2}$. Segundo, com que objetos ela opera. Note que a dimensão é constituída em objeto, como a quantidade de informação necessária para localizar um ponto no plano ou no espaço. Sobre os objetos IR, $\mathrm{IR}^{2}$ e $\mathrm{IR}^{3}$ ela diz:

Azul: [...] O que que é o R pra mim? [ela traça uma reta na lousa] Pra mim é pegar todo o sistema nosso de numeração. Pra mim, seria isso aqui [ela faz riscos sobre a reta sugerindo pontos] todos os pontos, infinitos pontos, pra mim é R. Se eu fizer mais uma [ela traça uma reta perpendicular à anterior] e colocar infinitos pontos aqui ó, pra mim é outro R. Agora se eu unir isso aqui infinitamente, pra mim é R2. Eu não sei se pra mim é tão /eu vejo assim, isso aqui tudo unido, certinho é o R2. Daqui, aí, tira um ponto fora, desse ponto que tá aqui fora eu relaciono aqui, eu faço o R3. [com a mão, ela sugere um ponto fora do plano da lousa]. Pra mim é isso. Eu não sei se eu tô simplificando alguma coisa demais, mas tenho essa visão. Eu acho assim, se eu quiser o R3 eu tenho eu tenho que tirar um ponto fora daquele R2, se eu ligar, eu tenho R3. Se eu conseguir montar uma terceira dimensão; se eu pegar um outro ponto fora dessa terceira e ligar, vou ter R4. Agora, eu não consigo visualizar essa quarta, o R4. Mas eu acredito que nesta mesma medida e proporção deve existir.

Logo, para ela, o objeto IR é constituído como a reta real; $\mathrm{IR}^{2}$, como o plano cartesiano e $\mathrm{IR}^{3}$, como o espaço físico. Assim, olhando desta perspectiva, não é possível obter $\mathrm{IR}^{3} \mathrm{de} \mathrm{IR}^{2}$, mas é possível obter $\operatorname{IR}^{2}$ e $\operatorname{IR}^{3}$.

Na sua fala, observo que ela, possivelmente, tenha ido aos livros-texto e lá tenha encontrado as definições de espaço vetorial, corpo e dimensão. Além disso, ela esteve presente às aulas em que 
Betty apresentou seu encaminhamento de resolução do problema e isto não alterou sua maneira de pensar. Notamos que ao longo das aulas, Azul foi silenciando. Ao longo de dois meses a totalidade de sua fala reduziu-se ao que foi apresentado anteriormente. Ao final desses dois meses de discussão, na aula em que a solução do problema foi apresentada, ela ainda comenta:

Azul: Interessante que desde o início, esse problema, eu achava assim, se fosse possível mudar, como você falou agora [referindo-se ao professor], "dimensão três, onde R2 é o conjunto de vetores desse espaço". Eu sempre achei que fosse assim. Mas, do outro jeito, eu acho difícil de entender isso. Por exemplo, se eu mudar isso aqui ó, assim, vão supor, se eu falasse assim: "investigue se é possível existir um espaço vetorial real de dimensão três, onde R2 é o conjunto de vetores do espaço". Pra mim, isso é claro assim. Se eu mudar isso aqui, eu não consigo perceber a mesma coisa. [...]. Não sei, pra mim, fica claro, eu consigo, assim, meu cérebro acha isso perfeito. Se eu mudar a ordem, não consigo encontrar razão pra isso. Eu acho interessante isso. Agora, se eu falar assim, "a dimensão três onde R2", aí, pra mim, faz razão. Eu não consigo encontrar a mesma razão no outro texto. Não tem assim, como provar isso. Eu tô pensando, porque só mudando a sequência, muda pra mim, a razão. Se eu falar isso, é desde o início. Lembra que eu comentei que, pra mim, mudando, eu via nitidamente que sim. É interessante, eu não consigo encontrar a razão. Eu tenho que pensar bem, até que conexão tá fazendo o meu cérebro, pra entender, de uma maneira assim. Que é desde o início que eu tava com a mesma dúvida. [...]

Ao que parece, Azul opera em relação ao que é o dado para ela. Ela passa por todo o processo operando com os objetos $\mathrm{IR}^{2}, \mathrm{IR}^{3}$ e dimensão, como elucidamos anteriormente; seu núcleo se mantém estável, isto é, as estipulações locais - a dimensão do $\mathrm{IR}^{2}$ é 2 e a dimensão do $\mathrm{IR}^{3}$ é 3 - se mantêm fixas, não transformando durante o processo.

\section{Considerações Finais}

A observação da maneira de operar de Betty e dos outros sujeitos de pesquisa nos leva a falar em processo de nucleação ao invés de apenas dizer núcleos, isto é, um processo de constituição e transformação de estipulações locais e, como consequência, de transformações nas operações e suas lógicas.

A leitura das ações enunciativas dos sujeitos de pesquisa revelou que os núcleos podem, ao longo do processo de produção de significados, sofrer mudanças, transformações nas estipulações locais com maior ou menor intensidade, ou se manter estáveis, no sentido de que as estipulações locais se mantêm as mesmas durante o processo.

No processo de nucleação de Betty, observamos algumas estipulações sendo constituídas e depois se afastando, dando lugar a outras e essas últimas, elas próprias, passando por mudanças com a incorporação de novos elementos. 
No processo de nucleação de Ades, por exemplo, não observamos o afastamento, nem a aproximação de estipulações locais, pois o movimento, nesse caso, se deu através de uma crescente incorporação de "novas" estipulações ao núcleo, em relação às já constituídas.

Diva parece não constituir o problema proposto em texto, para o qual ela não produz significados que possibilitem que ela resolva a questão proposta. Ela não opera com a ideia de que um espaço vetorial é uma estrutura algébrica, que dimensão em Álgebra Linear é um conceito algébrico - número de vetores de uma base. Suas estipulações locais se mantém as mesmas ao longo de todo o processo.

O processo de nucleação, observado na produção de significados de Azul, apresentou núcleo constituído ao longo de todo o processo pelas estipulações locais: " $\mathrm{IR}^{2}$ é o plano", "IR ${ }^{2}$ tem dimensão dois", "IR ${ }^{3}$ é o espaço", "IR ${ }^{3}$ tem dimensão três", com dimensão se referindo à quantidade de informação de que necessitamos para localizar um ponto no plano e no espaço. Tais estipulações locais se mantiveram fixas ao longo de todo o processo.

Nosso estudo revelou que os sujeitos de pesquisa produziram significados diferentes para o problema proposto (sendo que para alguns o problema era um resíduo de enunciação para o qual não produziram significados na direção de resolvê-lo) e que isto indicou a existência de diferentes núcleos a partir de onde eles operavam, sugerindo que, de fato, em cada caso existe uma dinâmica dos núcleos que podem ser, em alguns casos estáveis - quando há um conjunto de estipulações locais fixas - e em outros casos instáveis - quando sofrem mudanças e transformações a partir do afastamento de algumas estipulações e incorporação de novas estipulações. Logo, sugerimos que não existe uma dinâmica dos núcleos, mas dinâmicas peculiares a cada sujeito.

\section{Referências}

André, M. E. D. A. Etnografia da prática escolar. 16 ed. Campinas: Papirus, 2009 (Série Prática Pedagógica)

BOGDAN, R. C.; BIKLEN, S. K. Investigação qualitativa em Educação: uma introdução à teoria e aos métodos. Portugal: Porto Editora, 2013.

BRUNER, J. Realidade Mental, Mundos Possíveis. Porto Alegre: Artes Médicas, 1997.

GOODMAN, N. Of mind and other matters. London: Harvard University Press, 1984.

LINS, R. C.; Gimenez, J. Perspectivas em aritmética e álgebra para o século XXI. Campinas: Papirus, 1997. (Coleção perspectivas em Educação Matemática).

LINS, R. C. Por que discutir teoria do conhecimento é relevante para a Educação Matemática. In: Bicudo, M. A. V. (org.). Pesquisa em Educação Matemática: concepções e perspectivas. São Paulo: Editora da UNESP, p.75-94, 1999. 
LINS, R. C. The production of meaning for algebra: a perspective based on a theorical model of semantic fields. In: Sutherland, R. et al. (Ed.). Perspectives on school algebra. London: Kluwer Academic Publishers, p.37-60, 2001.

LINS, R.C. O Modelo dos campos semânticos: estabelecimentos e notas de teorizações. In: Angelo, C.L. et al. (orgs.). Modelo dos Campos Semânticos e Educação Matemática: 20 anos de história. São Paulo: Midiograf, 2012.

SILVA, A.M. Sobre a Dinâmica da Produção de Significados para a Matemática. 2003. 243p. Tese (Doutorado em Educação Matemática) - Instituto de Geociências e Ciências Exatas. Universidade Estadual Paulista, Rio Claro/SP, 2003.

SILVA, A. M; LINS, R.C. Sobre a Dinâmica da Produção de Significados para a Matemática. Jornal Internacional de Estudos em Educação Matemática, v.6(2), p.01-30, 2013.

VIGOTSKII, L.S; LURIA, A.R.; LEONTIEV, A.N. Linguagem, desenvolvimento e aprendizagem. 3ed. São Paulo: ícone, 1988. 